\title{
Research on Preferential Policies of Value-added Tax for Epidemic Prevention and Control in China
}

\author{
Jiangyu Huang, Changgui Dong* \\ College of Big Data Application and Economics, Guizhou University of Finance and Economics, Guiyang, China \\ Email address: \\ 2756235790@qq.com (Changgui Dong) \\ ${ }^{*}$ Corresponding author \\ To cite this article: \\ Jiangyu Huang, Changgui Dong. Research on Preferential Policies of Value-added Tax for Epidemic Prevention and Control in China. \\ American Journal of Theoretical and Applied Business. Vol. 7, No. 2, 2021, pp. 47-53. doi: 10.11648/j.ajtab.20210702.13
}

Received: June 9, 2021; Accepted: June 25, 2021; Published: June 30, 2021

\begin{abstract}
The effect of Value-added Tax (VAT) preferential tax policies on epidemic prevention and control is a hot topic of academic attention. Fiscal and taxation policies are conducive to economic recovery and social development. One of the functions of tax revenue is to regulate economic operation, which plays an important role in stabilizing economic operation during the COVID-19 period. To leverage of tax revenue, the government can reduce the economic pressure of social members during the epidemic period through tax relief, and guide enterprises to develop in better fields. VAT is still the largest source of tax revenue in our country, and its role in regulating economic operation is also very important. VAT has a positive impact on economic operation, can increase the development of the public health market, and contribute to epidemic prevention and control and post-epidemic economic recovery. This paper studied the VAT tax incentives during the epidemic period, and compared and analyzed the GDP data of the tertiary industry in 2020. The COVID-19 epidemic had a serious inhibiting effect on the economic development. The study found that some deficiencies of the preferential VAT tax policies for epidemic prevention and control: the preferential VAT tax policies for epidemic prevention and control need to be improved; The preferential policies of value-added tax in the field of public health need to be strengthened and Indirect taxes, mainly VAT, need to be strengthened to ensure people's wellbeing. The following suggestions are put forward: defining the scope of application of VAT policy in epidemic prevention and control; formulating systematic preferential tax policies in the field of public health security and to safeguard people's livelihood as the goal of continuous improvement of China's direct tax and indirect tax system.
\end{abstract}

Keywords: Epidemic Prevention and Control, Value Added Tax, Tax Incentives

\section{Introduction}

The COVID-19 epidemic in 2020 has had a serious inhibiting effect on the social and economic development. According to the GDP data of the first quarter of 2020 released by the State Administration of Statistics, the year-on-year economic growth in this period is negative $6.8 \%$. In order to alleviate the economic pressure brought by the epidemic on enterprises, government departments have introduced many policies to cut taxes and fees. According to official data, the scale of tax and fee reduction is about 130 million yuan in 2018, 200 million yuan in 2019, and 250 million yuan in 2020 . And the Government Work Report in 2021, tax and fee cuts has continuing to be optimized and implemented. As an important measure of structural reform, tax and fee cuts has helped China move toward high-quality development. Value-added tax (VAT) is the largest tax category in China, and tax reduction and fee reduction on VAT can reduce the tax burden of enterprises to a large extent. During the period of 2020, China will issue preferential VAT tax policies related to epidemic prevention and control. This paper studied the preferential VAT tax policies for epidemic prevention and control in China and made a comparative analysis of the GDP data of the tertiary industry in 2020. The study found the problems existing in the VAT preferential policies in epidemic prevention and control, and put forwarded corresponding suggestions. 


\section{Theoretical Basis of VAT Tax Preference Under Epidemic Prevention and Control}

Many scholars at home and abroad have studied the economic effects of tax and fee reduction, focusing on the role of VAT in epidemic prevention and control. Kim (2019) proposed tax cuts to encourage enterprises to raise wages, which proved to promote not only capital investment, but also employment. [1] Falkenhall, Mnsson and Tano et al. (2020) argued that the reduction of VAT has a positive effect on turnover, total wages, employment, profit margin and net entry of firms. [2] He and Wang (2019) believed that the reduction of VAT rate and the expansion of the scope of VAT input deduction can significantly encourage enterprises to enter. [3] Chen and $\mathrm{Li}$ (2020) took VAT transformation and tax reduction as the starting point, and found that tax reduction could not only increase national employment at the macro level, but also improve labor productivity and fixed asset investment of micro enterprises, and reduce the substitution ratio of capital to labor. [4] In terms of tax policies to deal with public health security emergencies, Li et al,. (2020) believed that a complete long-term tax mechanism should be established to deal with public health security emergencies[5-6]. However, there are few studies on the effect of VAT tax incentives on epidemic prevention and control from qualitative and quantitative perspectives.

\subsection{Laffer Curve Theory and VAT}

As one of the main financial revenue of a government, tax plays a macro-adjustment role in the economy and has the function of internal stabilizer. The tax system of a country should give consideration to both the principle of efficiency and fairness so as to minimize the tax burden on taxpayers[7]. The implementation of the comprehensive replacing business tax with VAT in China in 2016 is to continuously optimize the tax system and eliminate the problem of double taxation. In modern tax theory, Laffer, a famous scholar of the supply-side school, explained the relationship between tax rate and tax revenue through Laffer curve. When the tax rate exceeds the apex of Laffer curve, the continued increase of tax rate will lead to the decline of tax revenue of a country's government. On the contrary, when the tax rate is lowered and the government chooses to reduce the tax rate, the government's revenue increases.

\subsection{Tax Multiplier Effect and VAT}

The government sector stimulates consumption and investment by reducing tax revenue, and the multiplier effect makes the increase of national income more than the reduction of government tax revenue. As an important task of supply-side structural reform, tax and fee reduction is a long-term tax policy of universal benefit. Tax and fee cuts were already mentioned in the Government Work Report for 2018, which also called for more aggressive tax cuts. According to the authorities, the scale of tax and fee reduction is about 130 million yuan in 2018, 200 million yuan in 2019, and 250 million yuan in 2020 . According to the data on tax cuts and fees, the scale of tax cuts has increased year by year. As the government said, the burden reduction of Chinese taxpayers is constantly increasing. Enterprises have more funds to invest in product upgrading and improve the competitiveness of products in the market. For natural taxpayers, rising disposable income can boost consumption. The tax multiplier can increase the income of the whole national economy [8]. The implementation of VAT tax reduction and exemption is an important factor to promote the multiplier effect.

\subsection{Theory of Tax Neutrality and VAT}

When the tax does not affect people's behavior or choice and does not destroy the effective allocation of resources, which indicates that the tax is neutral at this time. The current value added tax has a certain neutral effect, which is beneficial to the market's allocation of resources to a certain extent. The principle of tax neutrality requires that tax has as little impact on the economy as possible[9-10]. On January 1, 2009, the VAT was transformed from production-oriented VAT to consumption-oriented VAT, and the tax rate was also slowly simplified. China's VAT reform is constantly tending to the principle of tax neutrality. Only by ensuring tax neutrality as far as possible, can the economic development be more stable and the occurrence of public health emergencies be more effectively dealt with.

\section{Analysis on Preferential Tax Policies of VAT in Public Health Emergencies}

Emergent public health events have the characteristics of sudden, instability and injury. Its emergence not only threatens human life and health, but also causes huge economic losses to various countries, such as: SARS in 2003, avian flu in 2004, Wenchuan earthquake in 2008, influenza A (H1N1) in 2009 and global outbreak of novel coronavirus in 2020, among which the economic downturn caused by novel coronavirus in 2020 is very serious. Therefore, the development of our country must pay attention to the relationship between public health emergencies and economic development, and pay attention to the tax policies of government departments in emergencies, so as to promote the development of public health security.

\subsection{To Trace the VAT Policy of Public Health Emergencies in China}

In 2003, SARS hindered the development of domestic economy at that time, and all industries were seriously affected, especially civil aviation, catering, hotel and taxi, etc. SARS is an epidemic virus, which will cause great loss to human beings if it is not controlled. During this period, in order to reduce the impact of SARS on the economy and accelerate the resumption of work and production of enterprises, the state introduced relevant tax policies to deal 
with SARS. Since the SARS event in 2003, The government paid lots of attention to the development of public health. In the outbreak of bird flu in 2004, the State Administration of Taxation introduced a preferential tax policy of VAT collection and refund for poultry processing enterprises.

In 2008, the Wenchuan Earthquake extended the scope of VAT deduction to severely affected areas.

Compared with SARS in 2003, Novel Coronavirus 2020 has a wider range of effects. In addition to 5 -- VAT tax policy for epidemic prevention and control in 2020, the State Council meeting held on March 31, 2021 also confirmed other new regulations related to VAT, such as: On April 1, 2021, the VAT threshold for small scale taxpayers such as small and micro enterprises and individual industrial and commercial households will be raised from 100,000 yuan to 150,000 yuan on December 31, 2022.

\subsection{Influences of VAT Preferential Policies for Epidemic Prevention and Control on Tertiary Industry}

Coronavirus broke out in a large area at the beginning of 2020 , and the country immediately made an emergency plan, ordering the implementation of comprehensive city closure measures throughout the country that strict prevention and strict control. By then, the domestic economy had almost started to stagnate and the downturn was severe. The whole domestic industry has suffered huge economic losses as a result. Many economic indicators in 2020 are down compared with the previous year, especially the economic indicators in the first quarter of 2020 are obviously down. This chapter mainly makes a comparative analysis of the impact on China's tertiary industry during the COVID-19 period in 2020 .

\subsubsection{Analysis of Economic Data of Tertiary Industry}

The tertiary industry covers a wide range of industries, such as transportation, finance, accommodation and catering, leasing and business services, wholesale and retail, information transmission and information technology services, etc. Compared with the primary and secondary industries, the tertiary industry can promote the recovery of employment rate more quickly, better stabilize people's heart, and increase their confidence in fighting the epidemic.

From January to March, China imposed a complete city closure, which brought almost the entire industry to a standstill. The GDP growth of the tertiary industry in the first quarter of 2020 was negative $5.2 \%$ year on year. As the epidemic prevention and control work in China was carried out smoothly, all parts of the country were unsealed as appropriate after three months, and China slowly began to resume work and production and economic recovery. The GDP of the tertiary industry grew by $1.9 \%$ year-on-year in the second quarter, $4.3 \%$ year-on-year in the third quarter, and $6.7 \%$ year-on-year in the fourth quarter of 2020 . According to the growth chart of the tertiary industry in 2020 and GDP of last year, China's economy in epidemic prevention and control is recovering in an orderly way.

Table 1. Quarterly GDP of the Tertiary Industry in 2020

\begin{tabular}{|c|c|c|c|c|}
\hline & First quarter & Second quarter & Third quarter & Fourth quarter \\
\hline Absolute GDP of the tertiary industry (100 million yuan) & 152728 & 142595 & 135122 & 122680 \\
\hline Year-on-year growth $(\%)$ & $-5.2 \%$ & $1.9 \%$ & $4.3 \%$ & $6.7 \%$ \\
\hline
\end{tabular}

Table 2. GDP growth of the tertiary industry in the first quarter.

\begin{tabular}{ll}
\hline Industry & Growth (\%) \\
\hline Wholesale and Retail & -17.8 \\
Transportation, Warehousing and Postal services & -14.0 \\
Accommodation and Catering & -35.3 \\
Financial industry & 6.0 \\
Real estate industry & -6.1 \\
Information transmission, Software and Information technology services & 13.2 \\
\hline
\end{tabular}

Table 3. Growth of GDP of the tertiary industry in the whole year.

\begin{tabular}{ll}
\hline Industry & Growth (\%) \\
\hline Wholesale and Retail & -1.3 \\
Transportation, Warehousing and Postal services & 0.5 \\
Accommodation and Catering & -13.1 \\
Financial industry & 7.0 \\
Real estate industry & 2.9 \\
Information transmission, Software and Information technology services & 16.9 \\
\hline
\end{tabular}

In the first quarter of the tertiary industry, the accommodation and catering industry was the most severely affected. The GDP growth of the accommodation and catering industry declined especially significantly, with a year-on-year growth of negative $35.3 \%$. In terms of year-over-year growth, it was also the steepest decline. Wholesale and retail industry as well as rental and business service industry did not develop well in 2020, with negative year-on-year growth. Of course, some industries did not suffer much during the outbreak. Information transmission, software and information technology services, for example, showed positive year-on-year growth throughout the epidemic-affected year of 2020. 


\subsubsection{Tax Policy Analysis of Tertiary Industry and VAT}

In terms of the GDP data of the tertiary industry, although China's tertiary industry as a whole has gradually recovered. However, the tertiary sector's accommodation and catering sectors, wholesale and retail sectors and rental and business services sectors continue to require attention. In particular, the accommodation and catering sectors saw a sharp year-on-year decline in revenue. Small-scale taxpayers and individual industrial and commercial households are the main VAT taxpayers in accommodation and catering industry, wholesale and retail industry, rental service industry and other industries. Therefore, temporary preferential policies for these three industries can be appropriately increased.

\section{Analysis of the Effect of VAT Preferential Tax Policy on Epidemic Prevention and Control}

\subsection{Analysis on Preferential Policies of Value-added Tax for Epidemic Prevention and Control}

In view of COVID-19, the government has issued a series of preferential tax policies. The author collected the preferential tax policies of value-added tax in 2020.

Table 4. Analysis of preferential tax policies for epidemic prevention and control.

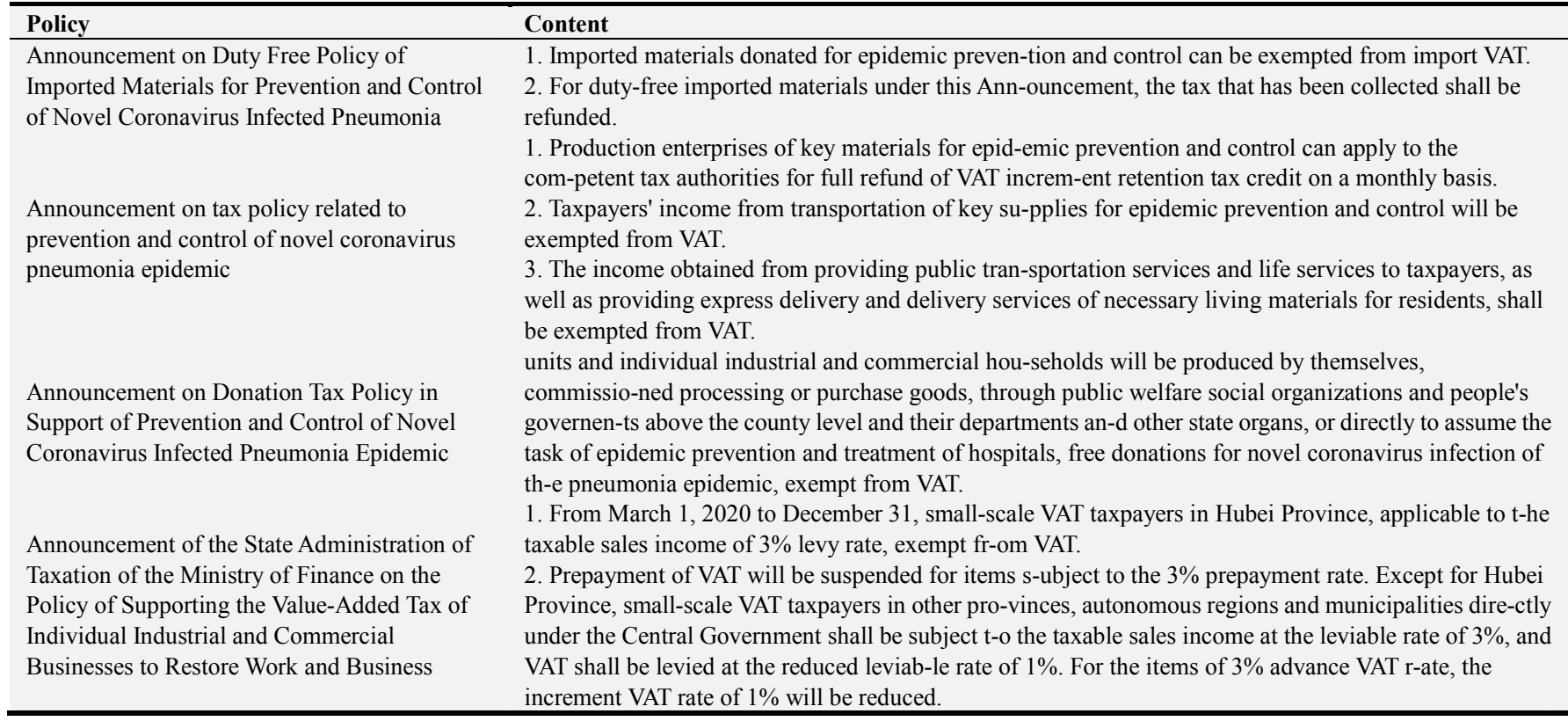

The above VAT tax policies on epidemic prevention and control are roughly divided into two categories. The first category is the tax reduction policies on epidemic prevention and control materials, which are mainly about the donation of materials and the production equipment of medical materials. The second category is related to the support of enterprises to resume work and production of tax relief policies.

\subsection{Value-added Tax Preferential Policy Role}

China's GDP for the whole year of 2020 reached 10.11598.6 trillion yuan, up 2.3 percent year on year, while GDP in the first quarter of 2020 grew -6.8 percent compared with the same period in 2019. In recent years, the state has been vigorously supporting tax and fee reduction, which is conducive to the steady growth of China's economy. VAT preferential policies for epidemic prevention and control have a positive effect on economic recovery.

According to the data from the first quarter to the fourth quarter, the economic losses were most severe at the beginning of the epidemic, but as the epidemic got better control and the cities were unsealed, the economy began to recover continuously. As the largest tax category in China,
VAT, its tax reduction can reduce the tax burden of taxpayers, stimulate economic growth and increase market investment, which plays a positive role in economic recovery after the epidemic.

\subsection{Regional VAT Preference for Epidemic Prevention and Control}

In China, the outbreak center of COVID-19 is Wuhan, Hubei Province. Since then, the number of cases in Zhejiang and Guangdong provinces has also been rising, compared with relatively few cases in Guizhou. The epidemic of 2020 is obviously regional, so it cannot be generalized when issuing corresponding tax policies for epidemic prevention and control. For example, Hubei, the most severely affected country, has introduced some VAT tax preferential policies applicable to Wuhan: From March 1, 2020 to December 31, Hubei small-scale VAT taxpayers, applicable to the taxable sales income of 3\% levy rate, exempt from VAT; Prepayment of VAT will be suspended for items subject to the $3 \%$ prepayment rate. The policy does not apply to provinces other than Hubei. By the end of 2020, the epidemic began to rebound in a small area, with the largest number of infected 
people in Hebei. Enterprises in Hebei will inevitably be affected by the epidemic rebound, and the country should also give tax incentives that are different from those in other provinces for this special period. Such as the extension of the tax incentive policy in 2020 to enjoy the time, for enterprises to reduce the burden.

Only by analyzing specific problems can we take precise measures to ensure that all parts of the country enjoy as fair tax treatment as possible. The state formulated different tax policies according to the different degrees affected by the epidemic to help enterprises resume work and production and restore the national economy. However, through the analysis of the preferential tax policies made by countries during the epidemic period, the author believes that the specific applicability of these temporary preferential policies needs to be improved. The current epidemic has entered a normal stage, and some areas may have a rebound at any time. To cope with this situation, the state department should make preparations in advance.

\subsection{Analysis of VAT Preferential Policies in Epidemic Prevention and Control}

According to the fiscal revenue data of 2020 released by the Ministry of Finance, the economic recovery during the epidemic period in 2020 was good. Tax cuts and fees played an important role, particularly the VAT tax preferential policy played a particularly important role. The reduction of VAT continues to stimulate consumption, promote investment and boost economic development. However, through the analysis of the VAT tax preferential policies that have been issued, as well as the comparison of the development of the tertiary industry and the public health field, the VAT tax policy in epidemic prevention and control needs to be improved.

\subsubsection{VAT Preferential Policies for Epidemic Prevention and Control Need to Be Improved}

According to the VAT tax preferential policies issued during the SARS prevention and control period in 2003 and the epidemic prevention and control period in 2020, the application scope of enterprises enjoying the preferential tax policies is unclear. Words such as "greatly affected by the epidemic" and "severe" are difficult to use specific criteria to measure.

According to the GDP data of some sectors of the tertiary industry in 2020, the growth percentage of catering and accommodation industry, retail and wholesale industry, and rental and business service industry in the same year is negative, indicating that the current phased VAT tax preference may not provide enough economic stimulus to these industries. VAT preferential policies for catering and accommodation industries, retail and wholesale industries and rental and business services need to be strengthened.

In order to continue to increase the intensity of tax cuts, the VAT reform has continued to be deepened in 2019. The 2019 VAT final incremental retention rebate greatly reduces the tax burden of many enterprises. It is only applicable to some advanced manufacturing enterprises and other eligible taxpayers. The preferential conditions are relatively harsh. In the government work report of March 2021, the preferential scope was extended to include new advanced manufacturing enterprises such as transportation equipment, electrical machinery, instruments and meters, pharmaceuticals, and chemical fibers. However, the scope of application is still narrow

\subsubsection{VAT Preferential Policies in the Field of Public Health Need to Be Strengthened}

After the outbreak of SARS in 2003, the government began to focus on public health. The government has been increasing investment in the field of public health, which is more directly reflected in the financial allocation. The temporary VAT preferential policies after the SARS outbreak in 2003 and the VAT tax preferential policies after the COVID-10 outbreak in 2020 are both aimed at preventing and controlling the epidemic and recovering the economy. But there are no leading tax incentives for public health. Many scholars have discussed the relationship between public health and economic development, who believe that there is a certain correlation between the development of public health and economic development, that is, the development of public health contributes to economic growth. Therefore, to achieve long-term economic development, we still need to strengthen public health development. In view of the status of VAT in China, its guidance in this field is not strong, and government does not really have a clear preferential VAT tax policy for the development of public health.

\section{Suggestions on Consummation of VAT Preferential Policies for Epidemic Prevention and Control}

Through the research and analysis of the VAT tax preferential policies for epidemic prevention and control in China, the relationship among tax preferential policies, economic recovery, enterprise resumption of work and production, and public health and security emergencies can be tested from the theoretical and practical situation [11-13]. According to the national VAT preferential policies for epidemic prevention and control, the problems in the tax preferential policies for epidemic prevention and control were found, and the following suggestions on VAT preferential policies for epidemic prevention and control were put forward based on these problems and literature.

\subsection{Defining the Scope of VAT Preferential Policies for Epidemic Prevention and Control}

In ancient China, the tax response to the epidemic was to promote the recovery of production after the epidemic by reducing the tax burden. And constantly reform the tax system in the epidemic, that is, to use the epidemic to promote the reform of the tax system. After the VAT reform in 2019, some scholars studied the economic effects of VAT reform and concluded that VAT is conducive to stimulating consumption, increasing investment and finally realizing economic growth. 
VAT plays a pivotal role in the prevention and control of the epidemic in 2020, but it is found that there are still need to be improved after research. The author believes that no matter in the normal epidemic prevention and control period of economic recovery, or long-term economic development, government should speed up the VAT legislation, so that VAT can be guaranteed at the legal level. Some vague concepts of VAT preferential tax policies in epidemic prevention and control should be determined as far as possible to facilitate the identification of enterprises. In addition, government should strengthen the VAT preferential policies for catering and accommodation industry, retail and wholesale industry and rental and business service industry.

\subsection{Formulate Systematic Preferential Policies on VAT in the Field of Public Health Security}

Taxation has the function of adjusting the industrial structure, and it can help people deepen their understanding of a certain industry. In the prevention and control of the epidemic, Internet big data, software industry and information technology service industry play an important role. According to the above analysis of GDP data of the tertiary industry, it is not difficult to see that they developed well during the epidemic, which is inseparable from the previous tax guidance of the country [14]. COVID - 19 to make people more aware of the importance of public health. In the normalized epidemic period, in order to make society more attention, and attention to the development of the field, the government should make for public health security appropriate preferential tax policies, such as research and development and production of the vaccines, drugs, medical equipment manufacturing and so on, and speed up the upgrading of industrial structure in public health security [15-16]. This can not only enhance people's confidence in defeating novel coronavirus, but also lay a foundation for responding to public health emergencies in the future. At the same time, it is far from meeting the requirements of normal epidemic prevention and control only based on the preferential tax policies of VAT. Government should combine the preferential tax policies of other tax types, learn from the experience and lessons of SARS and COVID-19, and formulate systematic preferential tax policies to deal with public health security emergencies.

\section{Conclusion}

In this paper, under the background of epidemic prevention and control and tax and fee reduction, the author studied and analyzed the VAT tax preferential policies for epidemic prevention and control as well as relevant literature. At the same time, the author made some comparative analysis on the preferential tax policies during the SARS period and the GDP data of the tertiary industry, and drew the following conclusions:

(1) Tax is one of the important means to regulate the national economy. Although the country has tried to increase the proportion of direct tax, indirect tax, mainly VAT, still has a high proportion of tax revenue at present. The COVID-19 epidemic can be used as an opportunity to further deepen the VAT reform and establish a tax system consistent with the modern financial system.

(2) After the study and analysis of VAT preferential tax policies, there are still shortcomings. For example, the definition of the policy is fuzzy. Through the comparison of the VAT tax preferential policies issued during the SARS period in 2003 and the epidemic prevention and control in 2020 , it is found that in the specific VAT tax preferential policies, the words such as serious and great loss have appeared. This gives the enterprise enjoys the preferential policy to identify to cause trouble. In terms of the GDP of the tertiary industry, the overall economy recovered well, but more attention should be paid to the accommodation and catering industry as well as the rental and business services industry. The importance of the area of public health security is self-evident, but there are few policies to support it. In the stage of epidemic normalization, tax policies should be adjusted according to the actual situation.

\section{Acknowledgements}

This research is financially supported by "Research on Cultivation of Big Data Thinking and Application Ability of University Undergraduates: Based on the Perspective of Digital Economy" (GZJG20200203).

\section{References}

[1] Kim S. Dynamic factor adjustment and corporate tax reduction in the Japanese manufacturing industry [J]. Journal of the Asia Pacific Economy, 2020 (08): 1-15.

[2] Falkenhall B, Mnsson J, Tano S. Impact of VAT Reform on Swedish Restaurants: A Synthetic Control Group Approach [J]. The Scandinavian Journal of Economics, 2018 (02): 824-850.

[3] He Zhen, Wang Xiaolong. Can Tax Reduction of Value-added Tax Inspire Enterprises? -- Empirical evidence from China [J]. Fiscal Studies, 2019 (07): 90-104.

[4] Chen Yian, Li Min. The Employment Effect of Tax Reduction in the "Transformation of Value-added Tax" -- Empirical Evidence from China [J]. Review of Labor Economics, 2020 (02): 117-137.

[5] Li Weiren, Wang Ying, Qiao Lele. Analysis on tax support policies for COVID-19 epidemic prevention and control [J]. Strait Technology and Industry, 2020 (07): 6-10.

[6] Yang Guangli, Sun Huiqing. Research on the Relationship between Macroeconomic Tax Burden and Economic Growth: An Analysis of Tax and Fee Reduction Policy Effect under the COVED-19 [J]. Price Theory and Practice, 2020 (12): 84-87.

[7] Li Na. International Comparative Analysis of Tax Policies for Supporting Epidemic Prevention and Control [J]. International Taxation, 2020 (04): 13-16.

[8] Mo Rong, Chen Yun, Bao Chunlei, etc. The impact of the COVID-19 epidemic on employment and the impact of the international financial crisis on employment $[\mathrm{J}]$. China Labor, 2020 (01): 16-30. 
[9] Ma Jie. SARS, Public Finance and Public Health [J]. Foreign Taxation, 2003 (07): 23-25.

[10] Yang Zhiwei. Tax Revenue Forecast Analysis of VAT Rate Reform [J]. Modern Marketing, 2020 (11): 198-199.

[11] Chen Xiaoguang. Taxation Countermeasures to "Bird Flu" [J]. Tax Collection and Collection, 2004 (06): 6-7.

[12] Li Ming, Wang Xiaodong. Discussion on Tax Policy for Responding to Public Health Emergencies [J]. Fiscal Science, 2020 (02): 17-23.

[13] Liu Changan. Economic Impact of "New Coronavirus" on
China and Fiscal Hedge Policy -- Comparative Analysis under the SARS Epidemic [J]. Lanzhou Journal, 2020 (04): 59-70.

[14] Shi Wei. The practice, thought and inspiration of tax revenue in ancient China in dealing with epidemic disasters [J]. Tax Research, 2020 (08): 138-143.

[15] Li Xiaolu. How to apply VAT preferential policies in enterprises under the epidemic situation [J]. Metallurgical Finance \& Accounting, 2020 (03): 38-42.

[16] Tian Zhiwei, Wang Zaitang. Research on the fiscal and economic effects of VAT reform [J]. Tax Research, 2020 (07): 26-31. 